\title{
Analysis on Customer Information Management System for Enterprise
}

\author{
Manlin Zhang \\ College of Economy and Law, Bohai University, Jinzhou, 121013, China \\ 793143130@qq.com
}

Keywords: enterprise; customer information; management system; system analysis

\begin{abstract}
With the development of market economy, competition is increasingly fierce, enterprises are facing greater challenges and opportunities, so how to maintain and develop customers is an important factor for enterprises to survive long term, therefore, the use of customer information management system is the developing trend in the future. This article conducts analysis from the execution process, application route, system composition, use case modeling and other aspects, it constructed the system constituted by customer information management, marketing management, sales information management, service and customer care, customer information analysis and other core functions, as well as data backup and recovery, code data maintenance, configuration information management, operating manuals, system help and other non-core functions. This research laid the foundation for the system development, which plays an important role to enhance the competitiveness of enterprises.
\end{abstract}

\section{Introduction}

With the rapid development and wide spread of computer technology, the application range of computer is no longer limited to simple scientific computing, but penetrated into all areas, such as education, industry and enterprise. Enterprise is the distribution center of production and management, and there is so much production data and enterprise customers' data, so it has to manage a lot of information data. The famous "80:20" theorem states that "80\% of a company's income comes from $20 \%$ of the customers," so, complete customer information management and service is the key for enterprises to get $80 \%$ of income from $20 \%$ of the customers. According to the attention center, development stage of enterprise from the "product-centric" and "sales-centric" to the "profit-centric", now it has entered into a "customer-centric" stage. Therefore, it is necessary to apply computer technology and information technology to the enterprise customer information management to form a new management model [1, 2].

In the traditional enterprise customer information management model, leaders or sellers record the customer information in their notebooks or computers by manually, these information can not be updated and shared, therefore, it often result in the loss of customer information, or delay of the product submission resulting in unnecessary loss, it may misses opportunities because of information loss. Using computer technology to develop customer information management system to manage enterprise customers' information, which is a new management model. Even though the market is constantly changing, rely on the information management system, enterprises can fully grasp the customer information to win in the competitive economic tide. The paper designs enterprise customer information management system based on JSP technology to provide technical support for software development.

\section{Analysis on Execution Process}

JSP (Java Server Pages) is designed to simplify the Servlet, which is a dynamic web technology standard advocated by Sun Microsystems and established by many companies. Java program section and JSP tag should be inserted into traditional HTML Web page file to form a JSP file that suffix is *.jsp. Web applications developed by JSP can be used cross-platform, it can run both on Linux and other operating systems, which achieved java extension in Html syntax. The same as 
Servlet, JSP performs on the server side. Usually returned to the client is HTML text, so client side will be able to browse if it has browser [3].

JSP technology codes tags and scriptlets of class XML used Java programming language to encapsulate the processing logic to generate dynamic pages. Web page can also access the application logic of resources in the service side through tags and scriptlets. JSP separates the display of web page logic and design and supports reusable component-based design to make the development of Web-based applications quick and easy. JSP is a dynamic page technology, the purpose of it is to separate the presentation logic from the Servlet. Java Servlet is the technology base of JSP, and large-scale Web application development requires both Java Servlet and JSP to complete. JSP has all the characteristics for the Internet of Java technology, such as easy-to-use, fully object-oriented, platform-independent, security and reliability. Execution process of JSP is shown in Fig. 1.

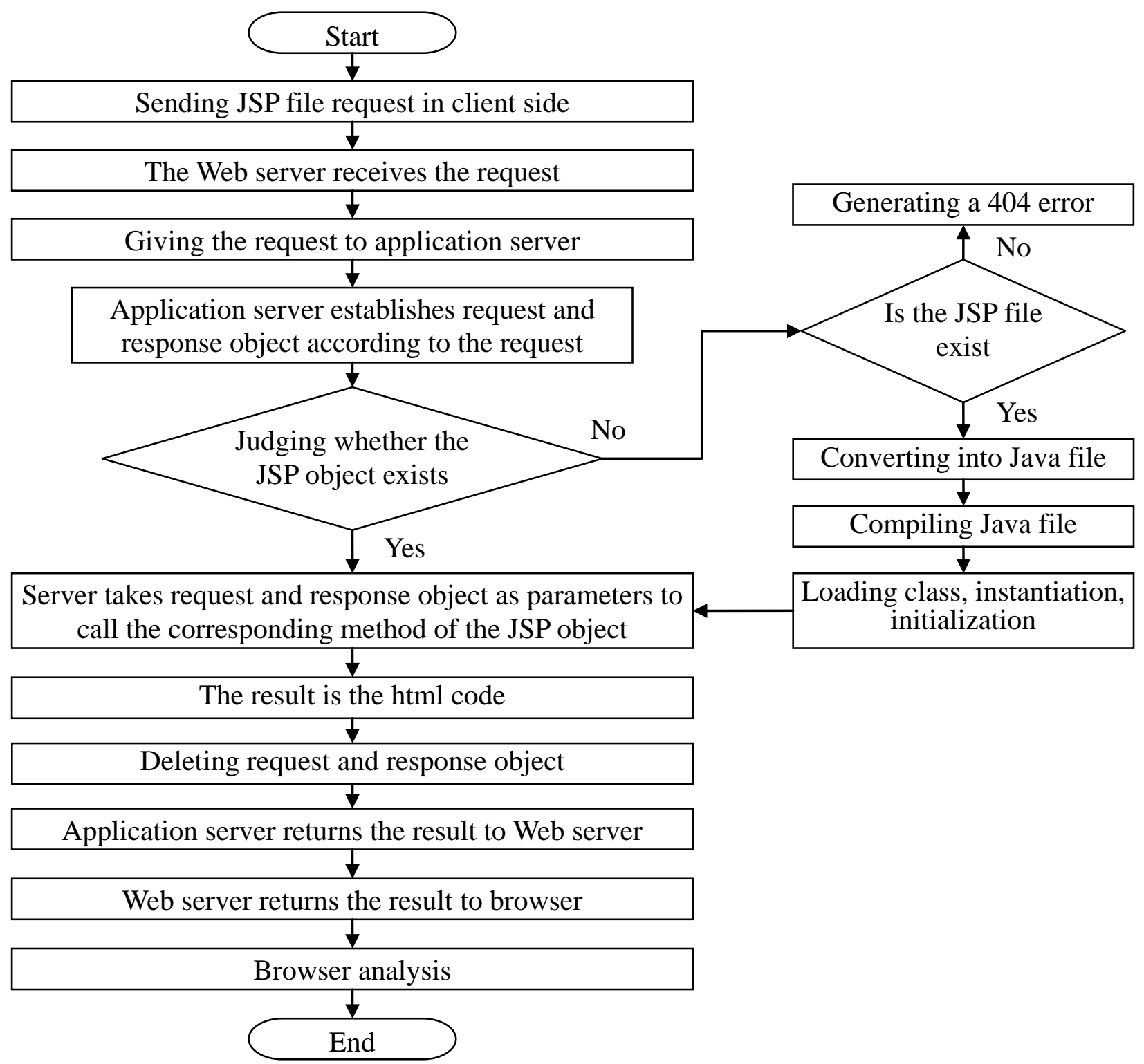

Fig. 1. JSP execution flow 


\section{Analysis on Application Route}

Application of enterprise customer information management system in manufacturing is not an overnight thing, the implementation phase is only paving the way, in order to express the enterprise's marketing service up and running, we need to adhere to long-term business. Application route is divided into the following four stages:

The first stage: accumulating the data from marketing, sales and service business, integrating customers/partners information, meeting the general needs of the inquiry statistics, preliminary finding value customers/partners, controlling business process, forming sector-level co-operation initially;

The second stage: establishing quantitative evaluation system of enterprise, department and employee performance, building value pyramid for customers/partners/employees, improving satisfaction of customers/partners/employees, forecasting market sales in an basic accuracy, providing the basis for production and logistics, forming regional-level co-operation;

The third stage: conducting decision management in marketing aspects, providing the market demand for the research and development system, developing production according to the needs and organizing production logistics, establishing a customer value -oriented enterprise management mode, forming enterprise-level co-operation;

The fifth stage: customer information management system as an intermediate layer of enterprise management platform, integrating customers and business information, delivering information to the internal ERP/PDM system, building extended enterprise value chains, it is put on the market with more powerful and flexible skill.

\section{Analysis on System Composition}

Enterprise customer information management system has functions to collect, processing, store, manage, retrieve customer information and other functions, which is the man-machine system consists of people, hardware, software and data resources, the purpose of it is timely and correct to collect, processing, store, deliver and provide customer information to achieve the management, regulation and control of all the operation and maintenance activities in the organization, system composition is shown in Fig. 2.

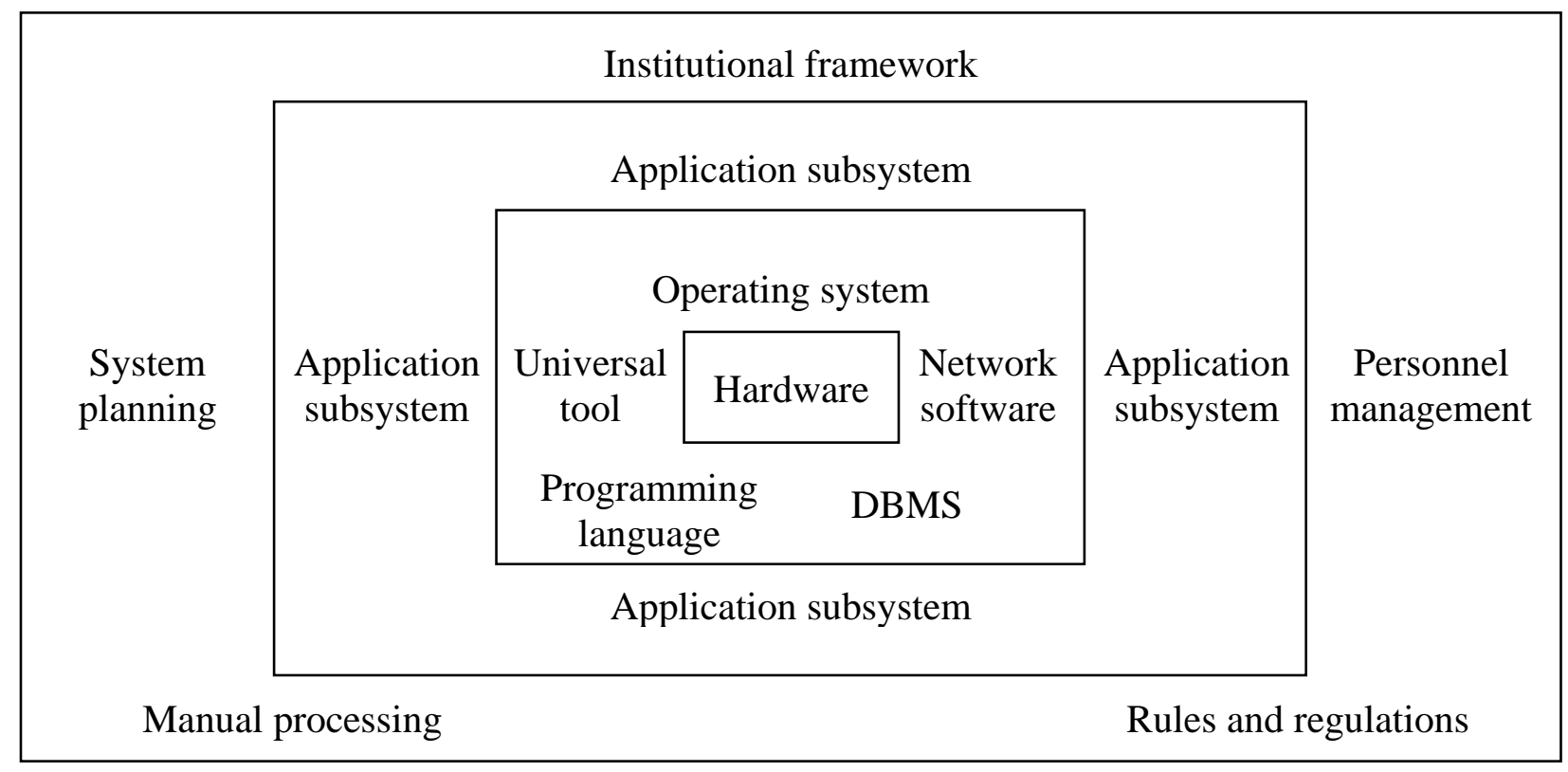

Fig. 2. System composition 


\section{Analysis on Use Case Modeling}

Demand analysis usually uses structured method, object-oriented method, prototyping method, use case modeling method and so on. Use-case modeling is used to describe the use cases, actors, a combination of relationship between use cases and actors in the designated system. Use case modeling uses the unified modeling language (UML) to provide modeling and visualization support for all phases in software development, including from requirement analysis to the specification, the structure and configuration [4]. There are three main models in UML system development, the first is functional model, displaying the functions of system from a user perspective, such as the use case diagram; the second is object model, using object, attribute, operation, correlation and other concepts to display the structure and foundation of system, such as class diagram; the third is dynamic model, it is used to show the internal behavior of the system, such as sequence diagram, activity diagram and state diagram [5, 6].

Use case from the user perspective to consider which specific goals computer can achieve to help developers get more demands. From the demand perspective, a case is an interaction between some external events and your computer. Use case diagram is considered to play a dominant role in the UML, which describes the visible behaviors in the external system. Therefore, in the case of considering system needs in software development, use case diagram determines a coercive power to drive and constrain the subsequent development.

Enterprise customer management system is "customer-centric", integrating enterprise resources through marketing, sales, customer, service, analysis and other core management functions to provide customers with "one to one" news service and maximum meet customers' demands, thereby customer loyalty will be enhanced. In addition to core management functions, it also includes non-core functions, such as data backup and recovery, code data maintenance, configuration information management, operating manuals and system help. Use case modeling is shown in Fig. 3 [7-9].

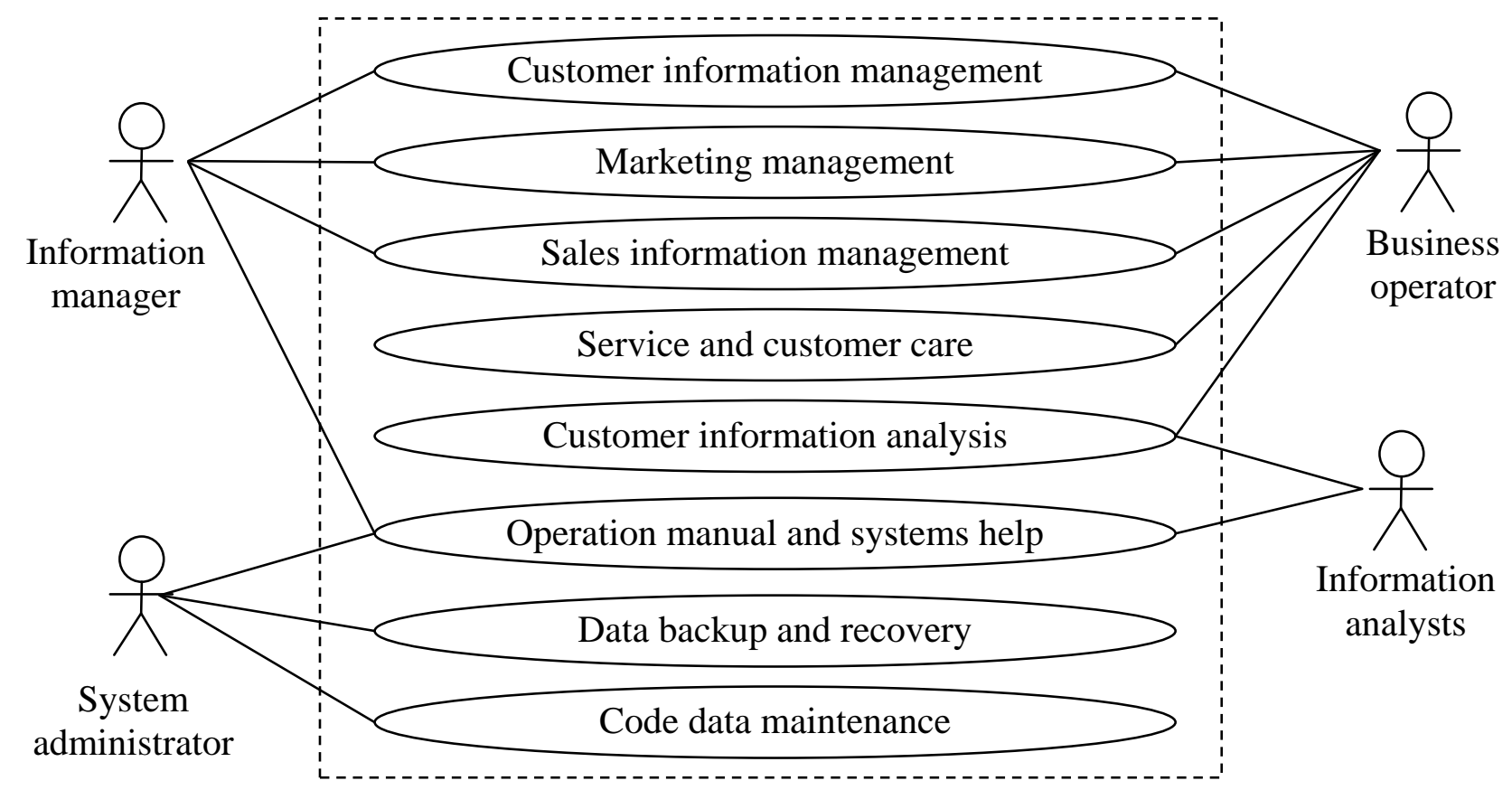

Fig. 3. Use case modeling

(1) The customer information management. Enterprise customer management system can record the customers' consumption information and classify and organize the customer information to solve the problems of forgetting the old customers and finding new customers blindly, through the system, enterprises can conduct market analysis and forecasting based on real data, and targeted develop and retain customers based on the results.

(2) Marketing management. Enterprise customer management system enables marketers to thoroughly analyze customer and market information according to the stored customer information 
in the system, the company's resources can be scientifically comprehensive classified and integrated in order to develop more targeted, more effective business marketing plan and then monitor and evaluate the marketing campaign effectively.

(3) Sales information management. Enterprise customer management system enables enterprises quickly grasp the latest developments of the market, such as always understand the latest consumer demand, expand sales channels, improve marketing programs to help enterprises speed their success in the market and increase market share to achieve enterprises' goals.

(4) Service and customer care. Customers can be understood in-depth through analysis of customer information to help enterprises take the initiative to grasp the needs of customers, through continuous, differentiated services means, to provide customers with more suitable products or services, and ultimately customer loyalty will effective upgraded.

(5) Customer information analysis. Through in-depth analysis of customer details to improve customer satisfaction, it is a mean to enhance the competitiveness of enterprises, mainly containing the analysis for customer profiles, customer loyalty, customer profitability, customer performance, customer future, customer product, customer promotion.

\section{Conclusion}

Customer information is an important information resource for enterprises to get benefit, the number of customer information is numerous and scattered, development of enterprise customer information management system is an essential basis for enterprises to implement modern management mode, which plays a pivotal role in improving enterprise efficiency. The key to ensure the success of the development of enterprise customer information management system, is to follow advanced software development specifications throughout the system development process, namely using advanced model concept in the software architecture design phase, relying on advanced software technology in the system implementation phase. Also you must fully understand the business information and needs, only in this way that you can develop an enterprise information management system with international advanced level suitable for enterprise demands. Contents of this paper laid a foundation for the development of enterprise customer information management system.

\section{References}

[1] Jeh-Nan Pan, Hung Thi Ngoc Nguyen, "Achieving customer satisfaction through product-service systems," European Journal of Operational Research, vol. 247, no. 16, pp. 179-190, 2015.

[2] Sartika Kurniali, Titan, "Customer Service Information System for a Call Center," Procedia Computer Science, vol. 59, no. 1, pp. 298-304, 2015.

[3] Baidu Encyclopedia, "Java server page," http://www.baidu.com/s?wd=JSP\&tn=synacast_2_adr, 2015-8-28.

[4] Baidu Encyclopedia, "Unified Modeling Language (UML)," http://baike.baidu.com/link?url=qNuGC3UcB1DGxJcX6dwOgncEGMw9yEFRe-NeJU7hoh_7 Ha0QKhLvRlLBU1wejvYfxc3ul3xtlYXkTj_VEvlotyZRCEQVd-ANc6M, 2015-8-28.

[5] Zamira Daw, Rance Cleaveland, "Comparing model checkers for timed UML activity diagrams," Science of Computer Programming, vol. 111, no. 11, pp. 277-299, 2015.

[6] T. W. Zhang, S. Y. Liu, "Application of UML in System Demand Analysis," Journal of Yangtze University (Natural Science Edition), vol. 3, no. 1, pp. 66-68, 2006. 
[7] Hsin Hsin Chang, Kit Hong Wong, Po Wen Fang, "The effects of customer relationship management relational information processes on customer-based performance," Decision Support Systems, vol. 66, no. 10, pp. 146-159, 2014.

[8] Paul Harrigan, Geoff Soutar, Musfiq Mannan Choudhury, et al, "Modelling CRM in a social media age," Australasian Marketing Journal, vol. 23, no. 2, pp. 27-37, 2015.

[9] Aurora Garrido-Moreno, Nigel Lockett, Víctor García-Morales, "Paving the way for CRM success: The mediating role of knowledge management and organizational commitment," Information \& Management, vol. 51, no. 8, pp. 1031-1042, 2014. 